\title{
Activismos juveniles en contextos de violencia. Subjetividad, emociones y cuidados en la Ciudad de México. Reflexiones desde la pandemia*
} Youth activism in contexts of violence. Subjectivity, emotions,
and care in Mexico City. Reflections from the pandemic

Ativismos juvenis em contextos de violência. Subjetividade, emoções e cuidados na Cidade do México. Reflexões a partir da pandemia

Héctor Rodolfo Andrade López**

\section{RESUMEN}

Esta investigación centraliza el "nivel subjetivo" de los y las acti-

Palabras clave: vistas jóvenes en la Ciudad de México, profundizando sus expeactivistas, emoriencias y acciones en los ejes de las "emociones" y la "ética del ciones, ética del cuidado" entre 2011 y 2021. Se aprovecha el periodo de la cuidado, jóvenes y pandemia por COVID-19 para construir una reflexión conjunta entre el investigador y los activistas entorno a las acciones violencia disciplipolíticas y la violencia disciplinaria de sus vidas cotidianas. naria.

Expone la preva-lencia de la "alegría" frente al "dolor" y el "miedo", así como un fortalecimiento de sus redes sociales como salidas propias a los impactos generados por dicha violencia. Por medio de entrevis-tas en profundidad y etnografía, este texto expone la dimensión y sofisticación de la violencia disciplinaria frente a los activismos de las juventudes, demarcando algunos matices del género fe-menino que generan violencia sexual frente a las activistas. A la vez, muestra algunas tácticas de cuidado que se implementan para salvaguardar la vida de sus integrantes, así como sus limita-

* $\quad$ Este artículo se desglosa de mi investigación en el Doctorado en Estudios Latinoamericanos de la Universidad Nacional Autónoma de México (UNAM), y es financiado por el Consejo Nacional de Ciencia y Tecnología (CONACYT, México).

** Mexicano. Doctorante en Estudios Latinoamericanos en la Universidad Nacional Autónoma de México y en Ciencias Políticas y Sociales de la Université Catholique de Louvain. Louvain-la-Neuve, Bélgica. hectorlandrade4@gmail.com 
ciones y contradicciones al requerir el apoyo de instituciones de la sociedad civil y del Estado.

\begin{abstract}
This research focuses on the "subjective level" of young activists in Mexico City, deepening their experiences and actions on the axes of "emotions" and "ethics of care" between 2011 and 2021. The COVID-19 period is used to build a joint reflection between the researcher and activists on political actions and disciplinary violence in their daily lives. It exposes the prevalence of "joy" as opposed to "pain" and "fear" and maintains their social networks as solutions to the effects generated by such violence. Through in-depth interviews and ethnography, this text exposes the dimension and sophistication of disciplinary violence against youth activism, demarcating some nuances of the female gender that generate sexual violence against activists. At the same time, it shows some of the care tactics implemented to safeguard the lives of its members and their limitations and contradictions in requiring the support of civil society and state institutions.
\end{abstract}

\section{RESUMO}

Esta pesquisa centraliza o "nível subjetivo" dos e das jovens ativistas na Cidade do México, com o aprofundamento de suas experiências e ações nos eixos das "emoções" e da "ética do cuidado" entre 2011 e 2021. Utiliza-se o período da pandemia da covid-19 para construir uma reflexão conjunta entre o pesquisador e os ativistas em torno das ações políticas e da violência disciplinar de suas vidas cotidianas. Expõe a prevalência da "alegria" em comparação à "dor" e ao "medo", bem como um fortalecimento de suas redes sociais como saídas próprias para os impactos gerados por tal violência. Por meio de entrevistas aprofundadas e de etnografia, este texto expõe a dimensão e a sofisticação da violência disciplinar frente aos ativismos das juventudes, demarcando alguns matizes do gênero feminino que geram violência sexual em relação às ativistas. Mostra, por sua vez, algumas táticas de cuidado implementadas para proteger a vida de seus integrantes, bem como suas limitações e contradições ao solicitar o apoio de instituições da sociedade civil e do Estado.
Keywords: activists, emotions, ethics of care, youth, and disciplinary violence.

Palavras-chave: ativistas, emoções, ética do cuidado, jovens e violência disciplinar. 


\section{Introducción}

A más de un año de la declaración de pandemia por COVID-19, diversos países de América Latina han recibido severos golpes a causa de sus dimensiones geográficas, económicas y políticas, padeciendo daños como altas cifras de contagios, decesos, dificultades para adquirir vacunas y rehabilitar la economía. En este escenario tan complicado, no han hecho falta los disgustos populares que exigen mejores condiciones de vida y derechos sociales. Sin embargo, la pandemia se torna como una justificación para hacer caso omiso de estas exigencias e imponer el brazo duro de las fuerzas estatales extendiendo los toques de queda, la vigilancia y la represión policial, al mismo tiempo que se tolera el incremento de distintas violencias en contra de la población.

De igual modo, el confinamiento en varios países latinoamericanos ha fungido como una justificación para inhabilitar las movilizaciones sociales. A través de distintos llamados, las autoridades han insistido en la necesidad del resguardo en casa y la mínima exposición a aglomeraciones, incentivando así el valor del individualismo en nuestras sociedades. Este llamado a no salir del hogar ha sido desafiado por la acción colectiva multitudinaria solo en pocas ocasiones. Sin embargo, este hecho, valorado en términos cuantitativos, omite otras escalas de los movimientos sociales durante el confinamiento.

Durante la crisis sanitaria se han implementado diversas regulaciones de movilidad y aglomeración en las urbes, aminorando la presencia pública de la acción colectiva. No obstante, resulta un grave sesgo analítico asumir la inexistencia o la desmovilización de movimientos sociales por el simple hecho de que no hay una frecuencia de grandes multitudes en las calles. Para poder ver a los movimientos sociales, cuando estos no son mediatizados, no hay que mirar a las multitudes, sino a los sujetos que ejercen la acción. Hay que asumir que los movimientos sociales tienen una dimensión subjetiva y una acción a microescala que es necesario profundizar.

En este sentido, esta investigación se alinea con las perspectivas que analizan los cambios, acciones y consecuencias biográficas del activismo (Giugni, 2008; Hart, 1996; Pleyers, 2018a). Parte del hecho de que los movimientos sociales mantienen dimensiones ubicuas y culturales y de que durante una pandemia como la actual, se torna necesario 
comprender y profundizar estos fenómenos, ya que el confinamiento generado por el virus SARS-CoV-2 no solo representa un escenario de mayor visibilización de las desigualdades del sistema neoliberal, sino también un espacio con mayores posibilidades de observación de los movimientos sociales a un nivel subjetivo y de microescalas. Poner la mirada en los movimientos activos durante la pandemia bajo estas perspectivas abre la posibilidad de mirar y comprender las propuestas del cambio social, ya que es precisamente en las vidas cotidianas de los activistas donde se gestan y practican valores de solidaridad, resistencia, apoyo mutuo y democracia (Bringel y Pleyers, 2020).

Esta investigación realiza una reflexión situada en la pandemia del virus SARS-CoV-2 que mira el periodo de 2011-2021, tomando en cuenta que diez años atrás el mundo se vio sorprendido por el inicio de un ciclo de movilizaciones sociales que partieron de Tunes, Libia y España y en poco tiempo emergieron en América Latina (Castells, 2012; Modonesi, 2017; Romanos, 2016). Este ciclo en la Ciudad de México (CDMX, en adelante), contó con diversos movimientos y protestas como el respaldo social al Movimiento por la Paz, Justicia y Dignidad, el \#YoSoy132, el \#PosMeSalto, las movilizaciones pro Ayotzinapa, las pro CENTE, el \#19S, las protestas feministas, las manifestaciones de víctimas de las y los desaparecidos, y las de las y los ambientalistas y periodistas violentados, entre muchos otros, en los cuales diversos jóvenes se involucraron, reafirmaron y/o se tornaron activistas.

Los movimientos y protestas de dicha década generaron diversos procesos de subjetivación en centenas de jóvenes capitalinos, los cuales emprendieron nuevos proyectos, y acciones políticas, nutriendo sus experiencias y aprendizajes (Andrade, 2018; Modonesi, 2017). Sin embargo, la continuidad de sus acciones se vio afectada por el arribo de la pandemia por COVID-19, la que obligó a distintos movimientos a resguardarse en casa y disminuir su presencia en los escenarios públicos. Esta inesperada intervención del confinamiento orilla al planteamiento de saber: ¿qué elementos de subjetividad encontramos en los jóvenes activistas de la CDMX durante la década de 2011-2021?

Debido a que buscar la presencia de grandes movimientos sociales en la arena pública resulta por ahora complicado, este trabajo ofrece una visión subjetiva de los movimientos de la última década presentes en las y los activistas jóvenes de la capital mexicana inmersos en la 
pandemia por COVID-19. Este aparente estadio de inactividad política ha sido aprovechado por esta investigación para explorar la autorreflexión, la experiencia, los sentires y las trayectorias de las y los activistas.

Partiendo de que la autorreflexión es un elemento indiscutible de la subjetividad y de que los activistas son sujetos organizados y cognitivos que forman parte de organizaciones complejas y que establecen vínculos entre el saber, el decir y el hacer (González, 2017), esta investigación dialoga con ellos y construye una epistemología que emana del esfuerzo del autor de este texto, así como de los propios activistas. Representa entonces una labor de "diálogo interepistémico" y un "trabajo de traducción" que permite a los activistas conversar acerca de las opresiones que resisten y producir una inteligibilidad mutua entre experiencias posibles y disponibles sin destruir su identidad (Santos de Sousa, 2003; 2006) ${ }^{1}$.

Debido a estos motivos se argumenta que durante la última década ha prevalecido en las y los activistas una persistencia de la alegría como la emoción que hace frente al dolor y al miedo, así como un fortalecimiento de sus vínculos de amistad y compañerismo que integra redes sociales de autocuidado. Ambas acciones se muestran como salidas propias de los impactos generados por la violencia disciplinaria y se mantienen aún en los tiempos de la pandemia.

Durante los últimos años se han realizado diversos estudios acerca de los movimientos sociales en relación con los protagonismos de las juventudes en América Latina. A raíz de las grandes protestas emergidas en años como 2011, en Chile y Colombia; 2012, en México; 2013, 2015 y 2016 en Brasil; y 2019, en Chile, Ecuador, Puerto Rico y Haití; diversos analistas han enfocado sus miradas en su interacción con el Estado, sus cronologías, el papel de las redes sociales y las oportunidades políticas (Cabrera y Salazar, 2015; González, 2015; Modonesi, 2017), ofreciendo de esta manera aportes relevantes para la comprensión colectiva de las movilizaciones. De igual forma, otros autores han

1 Durante la aplicación de las entrevistas en profundidad, se fomenta un diálogo con los activistas estimulando su autorreflexión en torno a las variables de interés del investigador. Sus relatos y reflexiones son interpretadas y objetivadas al momento de analizar toda la información recopilada en la investigación. 
realizado importantes investigaciones destacando el carácter subjetivo de los jóvenes que participan en estas movilizaciones. Trabajos como los de Dowbor y Szwako (2016); Nateras (2019); Loureiro et al. (2013); Poma et al. (2019); Reguillo (2017); y Valenzuela (2015a) se han concentrado en el entendimiento de las "identidades", "las emociones", las "prácticas políticas" y los "repertorios de acción" de los integrantes de los movimientos.

Esta segunda mirada enfocada en la dimensión subjetiva de los movimientos adquiere un papel importante para la comprensión de su continuidad. Puesto que concuerdan que los movimientos sociales no terminan una vez que las protestas han sido disueltas y han dejado de ser visibilizadas en los espacios públicos y en los medios de comunicación masiva. Es decir, ofrecen otra dimensión interpretativa del movimiento social, la cual se extrapola a las biografías de los actores participantes, abriéndonos la posibilidad de comprender los alcances culturales y políticos (no sistémicos) de los movimientos. Dicha dimensión nos brinda también la oportunidad de entender las acciones políticas subjetivas de las y los activistas en una crisis mundial como la generada por la pandemia.

\section{Metodología}

El desarrollo de esta investigación requirió de una metodología cualitativa centrada en la aplicación de entrevistas en profundidad y de una etnografía. Mediante la técnica de bola de nieve, fueron realizadas 17 entrevistas semiestructuradas con jóvenes activistas de la CDMX. Debido a las complicaciones de la pandemia, gran parte de ellas fueron hechas de manera online en las plataformas de Zoom y Google meet, pero también fue posible hacer algunas de forma presencial. El criterio de selección de los actores entrevistados se basó en localizar a jóvenes que hubieran participado y modificado sus vidas, a lo largo del periodo de movilizaciones 2011-2021, haciendo frente a la violencia disciplinaria (Reguillo, 2005). Del gran abanico de expresiones de activistas en la CDMX, solo fueron consideradas las autonomistas, feministas, y las relacionadas con el trabajo de Organizaciones de la Sociedad Civil (ODS), ya que ellas muestran distancia de las formas de participación política bajo estructuras tradicionales como partidos políticos y sindicatos, apegándose a modos de participación alternativos, más hori- 
zontales y autónomos (Pleyers, 2018a). Aunque se procuró una equidad de género en la selección ${ }^{2}$, los resultados emitieron 12 entrevistas a mujeres activistas y solo 5 a hombres. El número final fue determinado por la técnica saturación de datos.

$\mathrm{Al}$ abordar el delicado tema de la violencia disciplinaria desde la experiencia de las y los jóvenes activistas, los lugares mencionados en esta pesquisa y los nombres reales de las y los activistas han sido sustituidos aleatoriamente por otros, resguardando así su identidad y ayudando a la protección de sus integridades.

La información recopilada fue trabajada mediante el análisis de contenido centralizando la construcción y canalización de emociones a través de la designación de la expresión directa de la emoción y la expresión de emoción implicada ${ }^{3}$ (Plantin y Gutiérrez, 2009). De igual forma, el análisis de los relatos se centró también en la identificación de las acciones de ética común del cuidado (Álvarez y Auyero, 2014; Das, 2012). Ambas dimensiones fueron trabajadas paralelamente bajo el soporte teórico de la sociología de las emociones (Jaspers, 1998; 2012) y la vía de la subjetividad (Pleyers, 2018a).

El registro etnográfico se apegó a la propuesta del filósofo Luciano Floridi (2015) denominada etnografía onlife, cuya técnica, reúne la observación no participante en los espacios físicos y en las plataformas virtuales. Esta observación se llevó a cabo durante el periodo de confinamiento en la CDMX que inició en marzo de 2020 y se extendió para esta pesquisa hasta octubre de 2021. Se concentró principalmente en las redes sociales personales de Facebook de las y los activistas, así como en algunas de las transmisiones en Facebook de las protestas en vivo de algunos diarios nacionales como El Universal y de algunos co-

2 Con el interés de ser inclusivo y de matizar precisiones y diferencias de género en las relaciones de la violencia frente a los y las jóvenes activistas, esta investigación contempla la perspectiva de género en su diseño metodológico. Sin embargo, esta no representa una variable a profundizar, ya que dicha labor requiere ser abordada particularmente.

3 La expresión directa de la emoción refiere a la enunciación en primera persona de las emociones y la emoción implicada alude a emociones no designadas directamente, esta se infiere de las señales posteriores de la emoción (manifestaciones fisiológicas, gesticulaciones, conductas y posturas) y de las señales anteriores (narrativa y descripción que dan contexto al relato). 
lectivos de activistas y grupos de Derechos Humanos como La Cadera de Eva y la Brigada Humanitaria de Paz Marabunta.

\section{La caja de herramientas}

Para poder relacionar la violencia con los movimientos sociales de la década de 2011-2021 desde la subjetividad de los activistas, esta investigación ha realizado algunos cortes conceptuales buscando con ello, una mayor centralización y profundización del tema.

A sabiendas de la complejidad del concepto de violencia debido a sus diversas expresiones, dimensiones y entrecruces, esta investigación se concentra en la violencia disciplinaria entendiendo por esta, los mecanismos de represión implementados principalmente por las autoridades estatales, las élites económicas y los grupos de conflicto, con el objeto de someter, mediante el castigo ejemplar, a actores seleccionados y/o disidentes (Foucault, 1976; Reguillo, 2011; 2015). Esta violencia suele ser ejercida tanto en su expresión visible que engloba actos represivos y daños físicos y psicológicos, pero a la vez, también se encuentra prendida a las estructuras sociales y la cultura, las cuales mantienen también dispositivos y acciones que buscan el disciplinamiento y operan en mayor o menor medida de manera conjunta.

Por lo tanto, es posible entender que este disciplamiento es generado y reproducido por distintos actores como puede ser el Estado, el narcotráfico, los medios de comunicación y la misma sociedad cuando buscan disciplinar a los individuos en aras de intereses afines al estatus quo y sus beneficios (Foucault, 1976; Rosenbaum y Sederberg, 1975). En este sentido, es posible localizar esta violencia tanto en la reproducción de desigualdades sociales y en la criminalización de reglamentos de disidencia, como en los actos de represión policial, paramilitar, o de grupos de choque, en la intensificación y reconfiguración de policías, los actos de vigilancia, infiltración, persecución y estigmatización (Pleyers, 2018b).

Por otra parte, para poder comprender la permanencia de los movimientos sociales de la última década en los jóvenes activistas de la CDMX se hace uso de la elaboración conceptual "cultura activista centrada en la subjetividad" (Pleyers, 2018a), la cual centraliza el análisis de los movimientos sociales a un nivel de cambios locales y personales generados por los activistas. Para ello enfatiza la experiencia vivida, así 
como la experimentación de los actores. Los activistas defienden su experiencia vivida frente a los poderes económicos y políticos implementando valores y experimentando nuevas acciones más horizontales y autónomas en sus vidas.

La cultura activista de la subjetividad permite, por un lado, profundizar la experiencia de los y las activistas durante su participación en distintos movimientos sociales y protestas en la última década. Por otro, abre la posibilidad de enriquecer distintas expresiones del activismo juvenil contemporáneo. Esta investigación se enfatiza en activistas alejados de la participación en instituciones estatales y tradicionales como los partidos políticos, sindicatos y gremios estudiantiles, en jóvenes que han padecido la violencia disciplinaria durante la última década y que muestran experiencias, experimentaciones y expresiones de principios autónomos, horizontales y creativos que pretenden construir otro mundo a partir de sus prácticas y experiencias alternativas. Para ello, expone las expresiones feministas, autogestivas y la inmersión de activistas dentro del trabajo de organizaciones de la sociedad civil. Aunque estas expresiones no son las únicas en la CDMX, sí llegan a ser algunas de las más dominantes durante la última década y durante el confinamiento ${ }^{4}$.

La subjetividad de los y las activistas será abordada a partir de dos ejes. El primero, refiere a la dimensión emocional (Jaspers, 1998; 2012) por medio de la cual se enfatizan los significados culturalmente aprendidos que permiten a los sujetos organizar su experiencia privada, así como expresar abiertamente sus sentires frente a normas y acontecimientos sociales. En este eje se abordan las emociones que los activistas sienten, expresan y canalizan frente a actos de violencia disciplinaria. El segundo eje alude a la ética común del cuidado, entendida como el conjunto de pequeñas disciplinas que la gente común lleva a cabo para proteger a sus seres queridos y mantener una práctica ética en su vida cotidiana (Álvarez y Auyero, 2014; Das, 2012). Dentro de este eje se encuentran las medidas que realizan los activistas para protegerse a sí mismos de la violencia disciplinaria, como los monitoreos entre

4 Cabe aclarar que estas expresiones no representan categorías rígidas que separan a las y los activistas, por lo contrario, llegan a realizar entrecruces en sus experiencias. 
amigos, la creación de grupos, redes, códigos, lenguajes, comisiones de seguridad, etc.

\section{Resultados}

\section{Del dolor y el miedo a la prevalencia de la alegría}

Muchos de los estudios centralizados en el papel de las emociones en los movimientos sociales tienden a explicar cuáles son las emociones en el emerger, desarrollo y perecer de un movimiento, dejando en claro la importancia de las emociones en la resistencia, la motivación y los resultados obtenidos (Ariza, 2016; Poma, 2017; Poma y Gravante, 2016). Sin embargo, al localizar las emociones solo durante los procesos de gran movilización se corre el riesgo de pensar que estas también desaparecen junto con las protestas, negando así sus permanencias en la vida cotidiana de las y los actores.

Debido a estos motivos, esta investigación posiciona que las emociones no pueden ser cercenadas y reconocidas solo en ciertos periodos de alta movilización, ya que su papel continúa siendo de gran relevancia en las acciones cotidianas de los activistas.

La experiencia política de los activistas durante esta última década permite realizar una lectura conjunta de su participación en diversas movilizaciones y coyunturas. A sabiendas de una disminución de las grandes protestas públicas, la crisis civilizatoria y de salud por la que atravesamos actualmente (Bringel, 2020), ha permitido a los activistas poder realizar un esfuerzo reflexivo respecto de su participación en el periodo estudiado, así como la realizada actualmente a nivel subjetivo y a microescalas. Esta reflexión subjetiva realizada con los activistas ha permitido pensar las emociones frente a las violencias dirigidas a los movimientos sociales. Por ello asumimos que la evocación y canalización de emociones constituyen modos de lucha política en los activistas sometidos a los contextos de violencia disciplinaria.

En este sentido, se argumenta que la subjetividad de las y los activistas enfocada en las emociones alude a que en la última década el dolor y el miedo que afecta a estos jóvenes se contrarresta con un esfuerzo de expandir los sentimientos de alegría en los niveles individuales y las relaciones sociales de los activistas. 
Para los jóvenes entrevistados el dolor propio y ajeno representa el motivo principal para emprender acciones de protesta. Diversas crisis sociales y políticas han llevado a estos jóvenes a experimentar el dolor y la indignación en el transcurso de los últimos 10 años. Acontecimientos como la desaparición de los 43 jóvenes normalistas en Iguala Guerrero, los 9-10 feminicidios que se comenten día a día en el país (Reza, 2020; Saúl, 2019), las más de 82.000 desapariciones acumuladas por el combate contra el narcotráfico (El Economista, 2021), el encarecimiento del costo de vida en la ciudad, entre otros problemas, han sido detonantes de la acción para los activistas. Jaime, activista desde hace varios años y actual dirigente de una asociación civil que realiza investigación y acompañamiento psicológico para los movimientos sociales en México, relata su afectación ante esta dolencia cotidiana de la siguiente forma:

De pronto uno se levanta en la mañana, abre el periódico y se da cuenta que alguien allá lejos, lejos, lejos (...) perdió un hijo. O alguien lejos, lejos, lejos(...) está buscando una hija. $\mathrm{O}$ a alguien lejos, lejos, lejos(...) le quitaron su tierra. Todo eso es violencia. El tema, yo creo que no solo es cómo se define [refiere a la violencia], sino cómo se siente. Y ojalá todo el mundo lo sintiéramos de la misma forma; es decir, ojalá a todo el mundo se nos estrujara el corazón cuando oímos a una mamá buscando a sus hijos; cuando escuchamos a un indígena que le quitaron la parcelita que tenía porque es la única forma que tiene de vivir; ojalá a todos nos pasara cuando alguien está injustamente en la cárcel. Entonces la violencia es algo incómodo, es algo que duele, es algo que pesa, pero al mismo tiempo, es algo que uno tiene que asimilar porque así es la realidad, pero también uno tiene que actuar sobre eso y tiene que encabronarse, patalear, gritar, llamar la atención. (Jaime, comunicación personal, activista, CDMX, 2 de diciembre de 2020)

El testimonio de Jaime permite apreciar la sensibilidad ante el dolor de las personas ajenas. Este sentimiento de empatía representa un choque moral (Jaspers, 2012), al mostrar que para Jaime el mundo no es como lo piensa y que es necesaria una reelaboración de principios morales. La expresión "la violencia es algo incómodo, es algo que duele, es algo que pesa" nos abre la posibilidad de transgredir el fomento del individualismo de la sociedad capitalista, al entender que el dolor 
ajeno puede ser compartido. De igual forma las palabras "es algo que uno tiene que asimilar porque así es la realidad, pero también uno tiene que actuar" muestran que las violencias son cotidianas, al igual que el dolor que ocasionan y que es una situación intolerable que requiere de acción emergente.

En este sentido, podemos inferir que para los activistas el dolor ajeno es asimilado y compartido, sin embargo, no es soportado por ellos mismos, lo cual exige su canalización en otras emociones como lo es la alegría. Si las violencias son permanentes para muchos activistas, se torna entonces necesaria la persistencia de posicionar valores cotidianos que aminoren esas dolencias. Esta canalización de emociones es reflejada en el siguiente relato de Jairo, joven activista de acciones e ideologías autogestivas:

Es la frustración, ira, coraje que uno tiene ante los gobiernos, pero también ante el Estado, las empresas, las iglesias, a todo el mecanismo que oprime a los diferentes pueblos (...) Digamos que ese coraje, esa frustración fue algo que en algún momento me motivó, pero también me cansó. $\mathrm{O}$ sea, fue algo bien evidente que en algunos momentos decía: "ya estuvo. Ya me estoy enojando con todo el mundo. Ya con todo el mundo estoy estableciendo relaciones como espinosas" (...) Me interesa construir y esta parte me ha llevado a un buen de cosas. Creo que específicamente el tema de la autogestión y el "autogestival" ${ }^{5}$ me ha llevado a pensar que la vida se puede llevar de una forma muy distinta; sin pagarle impuestos al gobierno directamente, sin darme de alta en hacienda, sin trabajar para sus empresas, sus gobiernos, sus iglesias, un patrón o patrona gandalla, esa es una gran motivación. Una reivindicación de dignidad. Eso es algo que me motiva todo el tiempo.

Y bueno la verdad es que en 2013 yo conocí a un grupo de compañeros que abanderaba la alegría. Es decir que motivaban a que tus expresiones fueran alegres más allá de la risa, es decir, la risa puede ser una buena máscara. Diciéndolo así, la alegría profunda es algo que te lleva a imaginar estados de ánimo. Que a lo mejor estás serio,

5 Refiere a un encuentro de activistas autónomos que comenzó a gestarse en 2013 en la CDMX y logró acercar e intercambiar diversas expresiones autogestivas más allá de la capital del país. 
pero estás contento con lo que estás haciendo. Y entonces, en ese sentido, también me motiva mucho la alegría que se puede respirar dentro de los movimientos sociales. Dentro de los pequeños o grandes logros que de repente tenemos. De repente, sacar a algún compañero o compañera de prisión o conseguir que algún gobierno se eche pa' atrás en alguna lógica extractivista. Son logros por los que todo el tiempo se está luchando por ellos, entonces digamos que la alegría es algo que en contraste a lo de antes, pues sí me motiva todo el tiempo. Me motiva la alegría hacia la dignidad por así decirlo (...) A mí me motiva bastante, en compañía de compañeras y compañeros, producir elementos de dignidad que nos lleven a sonreír, a pasarla chido, a dignificar nuestras vidas y tratar de pasar la voz para que eso se haga más grande. (Jairo, comunicación personal, activista, CDMX, 28 de noviembre de 2020)

Las palabras de Jairo resultan más que atinadas para entender cómo es que el dolor puede canalizarse en alegría mediante la acción. Jairo se ha dedicado profesionalmente al diseño de manera independiente y ha montado en compañía de sus colegas una panadería autogestiva que transmite el conocimiento sobre el horneado de pan sin fines lucro e implementa una división del trabajo equitativa sin la necesidad de cadenas de mando. Tanto sus diseños como sus panes llegan a ser algunas de las aportaciones que brinda a otros movimientos sociales con el interés de solidarizar con sus luchas y generar emociones como la alegría. En el trayecto de los últimos años ha colaborado con los padres de los normalistas de Ayotzinapa, con asambleas barriales y con la Coordinadora Nacional de Trabajadores de la Educación (CENTE), y durante la pandemia ha apoyado con recursos de su panadería y sus diseños a okupas y proyectos antisistémicos.

La sociología de las emociones ha demarcado en repetidas ocasiones cómo es que estas han sido desvalorizadas bajo el dogma de que las emociones no son constructivas al no ser racionales (Ariza, 2016). Sin embargo, experiencias y relatos como el de Jairo muestran la potencia constructiva que pueden tener las emociones cuando son canalizadas. Este problema analítico ha sido en diversas ocasiones abordado por la antropóloga Rossana Reguillo quien, bajo una perspectiva spinoziana y deleziana, ha argumentado que los afectos que permiten aumentar la potencia son alegrías, mientras los que la que la disminuyen, son 
tristezas. En este sentido, en todas las sociedades los poseedores del poder viven de la tristeza de los otros, contrarrestando de esta manera la potencia constructiva de los dominados (Reguillo, 2015).

La canalización del dolor (que entristece) en alegría (que construye) pasa por la interiorización emotiva y reflexiva de los y las activistas, quienes optan por experimentar formas contrahegemónicas en sus vidas cotidianas como acciones de resistencia a las emociones que imponen las violencias como la disciplinaria. En palabras de Reguillo (2015, p. 134): "me entristece aquello que atenta o descompone mis relaciones con el mundo, me alegra aquello que ayuda a componer o crear nuevas relaciones con el mundo".

De acuerdo con este planteamiento, es posible apreciar cómo es que para las y los activistas como Jairo, el dolor se torna una emoción entristecedora que estatiza la capacidad de potencia, favoreciendo el dominio de las élites económicas y de los grupos políticos y de poder, por lo que requiere ser canalizada en alegría por medio de la acción (potencia), procurando mantenerla y compartirla constantemente, en la medida que sea posible.

Paralelamente al dolor canalizado en la alegría, encontramos también el miedo como otra emoción continua dentro de la experiencia de los y las activistas en los últimos 10 años de movilizaciones en la CDMX. El miedo ha sido relacionado principalmente con la represión política a la que están expuestos. La relación entre represión y movimiento social representa un pre-constructo cultural que siempre está presente en jóvenes activistas, y que data de saberes compartidos entre las distintas culturas activistas como son los actos de represión históricos del movimiento estudiantil de 1968, la guerra sucia de los años 70 , las constantes agresiones a las comunidades indígenas y los acontecimientos más cercanos como los 43 estudiantes desaparecidos de Ayotzinapa y los asesinatos del líder regional Samir Flores y de diversos periodistas en el país.

Las reflexiones construidas desde la pandemia muestran que recientemente los y las activistas tienen miedo a los actos represivos tanto del gobierno, como de los grupos paramilitares, y del crimen organizado. Ello, debido a diversas acciones represivas como las agresiones físicas, la vigilancia, la intimidación y la desaparición forzada 
que están muy presentes en el radar de los y las activistas. El temor a estas acciones muestra cómo es que la violencia disciplinaria es una acción cotidiana para estos jóvenes y no solo un acto represivo que se vive durante las acciones más visibles de protesta. Gran parte de las y los jóvenes entrevistados menciona temor por sufrir alguna de estas acciones de disciplinamiento, al igual que temen por el bienestar de sus familias y amistades, ya que son conscientes de que el daño al que están expuestos no solo puede generarse en sí mismos, sino también en sus personas más allegadas.

Este temor latente ha sido expresado por Fabián, activista de prácticas e ideologías autogestivas cuando le he solicitado compartir su experiencia y opinión acerca de los riesgos del activismo actual en la CDMX, teniendo en cuenta el cambio de gobierno del Partido Revolucionario Institucional (PRI) al partido de Movimiento de Regeneración Nacional (MORENA). Respecto de esta pregunta, Fabián emitió lo siguiente:

FABIÁN: La represión se ha modificado un poco, porque el gobierno de MORENA cuida más el costo político de detenciones. Por ejemplo, se vio con las marchas feministas, puede ser muy alto el costo político desde un gobierno que se dice de izquierda y es todo un reto, pero sigue siendo lo mismo. O sea, yo creo que han bajado las detenciones. Esa es mi impresión. No tengo las cifras, pero ha bajado el número de detenidos y lo digo porque ya no hemos escuchado que: "están otra vez detenidos", “ya los apañaron”, "hay que ir", "hay que hacer la vaquera”, “ ¿y los abogados?”.

Total, en ese sentido, mi impresión es que pueden generarse formas más violentas y confrontativas entre la misma banda, porque a la banda que trabaja en el gobierno de MORENA de la CDMX los habían obligado a participar como valla de seguridad en las protestas, y son ellos quienes se empiezan a confrontar con la misma banda. O sea, los que trabajan dentro del gobierno contra nosotros mismos, y eso me parece más perverso (...).

Creo que la represión ha disminuido... no podemos decir que se ha presentado en este periodo la misma brutalidad de antes. Pero en ningún momento es un agradecimiento, porque no tendría que ser de alguna otra forma. Digámoslo de alguna manera. O sea, no es 
un agradecimiento: "gracias por tratarme humanamente", "gracias por respetar mi derecho a manifestarme". Tampoco es un agradecimiento. Es lamentable que dado al grado de represión que ha habido, tengamos que reconocer que ha bajado. Es lamentable, pero hay compas de Atenco que nunca se recuperaron de ser violadas en ese tiempo (...) Aún así, pienso que la represión sigue, que continúa la vigilancia desde otras formas, quizá puedan ser más veladas en este momento, no están tan abiertas. A nivel federal habría que ver, porque la militarización no ha bajado. Chiapas sigue militarizado, la Montaña de Guerrero sigue militarizada, los puertos también... Los asesinatos a nivel federal no han parado.

Yo no soy una figura pública, tampoco soy lo más visible, también por seguridad, pero tengo compañeros que sí les ha pasado eso.

ENTREVISTADOR: $\mathrm{Y}_{¿}$ Cuáles son esos riesgos para un activista?

FABIÁN: Los riesgos son que te desaparezcan, te maten, que afecten y amenacen a tu familia, son los más explícitos. Los otros son la persecución, que te intervengan tu celular, por ejemplo. ¡Es brutal! Una compañera muy cercana estaba en Ixtapa Zihuatanejo realizando reportajes, se metieron a su casa, le robaron su cámara fotográfica, su computadora, la amedrentaron, etc. Es lamentable. Es algo que cada vez es más cercano, es todo eso. En algunos casos, ha pasado que el Estado les ha bloqueado cuentas de sus cooperativas de café. Dependiendo, si eres muy pequeñito a lo mejor basta con una pequeña acción, dependiendo de tu organización. A los compañeros de la cooperativa con los que trabajamos en San Sebastián, les han asesinado a 5 compañeros solo el año pasado. De ahí a todo lo que va. (Fabián, comunicación personal, activista, CDMX, 8 de agosto de 2020)

El testimonio de Fabián enuncia directa e implícitamente la presencia del miedo al ser activista en la CDMX. Extiende la percepción geográfica de la represión, ya que se siente expuesto a las agresiones que puedan acontecer en otras entidades del país y en relación con su amistad y compañerismo con otros activistas y movimientos sociales. Fabián realiza actualmente sus estudios de posgrado en una universidad pública, donde también es docente; él en conjunto de algunos compañeros ha construido una cooperativa de transporte que ofrece 
mudanzas y funge como vehículo de movilidad para otros movimientos sociales y cooperativas. Esta acción lo ha orillado a formar parte de una red de experiencias autogestivas y de luchas sociales en la región centro-sur del país, pero también lo ha expuesto a percibir y padecer las violencias de esas otras formas de lucha. Durante la pandemia, Fabián ha mencionado que sus actividades de la cooperativa no han disminuido, puesto que la movilidad en la ciudad es un problema estructural y una necesidad para las personas y las actividades económicas de los movimientos sociales $\mathrm{y}$, aunque la violencia que han padecido muchas de sus amistades lo atemorizan, no desiste en su proyecto. Su experiencia y testimonio verifican que la violencia disciplinaria no tiene fronteras geográficas y que el daño que padece un activista puede generarse en su misma persona o a través de otras.

El arribo de MORENA al gobierno local en 2018 es percibido positivamente debido a ciertas acciones como la desaparición del cuerpo de granaderos local o la negativa de la jefa de gobierno Claudia Sheinbaum de reprimir directamente las protestas, tal cual lo venían haciendo los mandatos predecesores del Partido de la Revolución Democrática (PRD) y del Partido Revolucionario Institucional (PRI); sin embargo, el miedo sigue latente debido a la permanencia e incremento de violencias en el resto del país.

Si bien el mandato de MORENA en la CDMX contiene algunos matices de disminución de violencia represiva en contraste con los gobiernos predecesores, cabe hacer mención de que dichos mecanismos represivos comienzan a sofisticarse. La reivindicación del feminismo y sus manifestaciones en la capital del país han permitido visibilizar otras tácticas disciplinarias que buscan la desmovilización de las activistas feministas.

Al respecto, el movimiento feminista en la CDMX actualmente mantiene un proceso de crecimiento debido al aumento generalizado de la violencia con su particularidad contra las mujeres, a la impunidad e ineficacia en el tratamiento de los delitos de género, y a la expansión de una animadversión de hombres contra mujeres debido a su empoderamiento (Álvarez, 2020). En los últimos meses el trabajo etnográfico de esta pesquisa, tanto presencial como virtual, detectó la presencia de un cuerpo policiaco femenino denominado "Las Ateneas" como una política púbica para la disminución de represión policial en 
contra de las protestas feministas en la capital. Este cuerpo disciplinario ha sido utilizado recientemente para limitar los trayectos de las marchas feministas bloqueando y encapsulando en diversas ocasiones a las jóvenes que consideran peligrosas.

Si bien es cierto que el movimiento feminista ha radicalizado sus acciones implementando pintas, incendios y otros daños a monumentos e instituciones públicas y privadas, cabe enfatizar que dichas acciones no representan el repertorio de todo el movimiento feminista, sino solo de una fracción. Sin embargo, esta radicalización funge como justificación para estigmatizar al movimiento feminista y permitir ciertos actos de represión en contra de las manifestantes.

Durante la última protesta feminista en la CDMX en conmemoración del \#8M de 2021, el cuerpo policial de Las Ateneas —en conjunto con algunos policías varones- encapsuló por horas a diversas manifestantes obedeciendo al estigma estético de las activistas que cubren sus rostros, visten de negro, son jóvenes y mantienen una energía álgida durante las protestas. Estos encapsulamientos han venido realizándose constantemente en cada manifestación pública feminista desde comienzos de la pandemia en México ${ }^{6}$.

Durante los últimos meses del 2020 diversas jóvenes feministas fueron citadas frente a las instalaciones de la Fiscalía General de Justicia (FGJ) de la CDMX, donde se les imputó el delito de "robo", "daños a propiedad ajena" y "daño a inmuebles" durante la toma de la Comisión Nacional de los Derechos Humanos (CNDH) y otras protestas. Estas acusaciones fueron basadas en carpetas elaboradas con fotografías, muchas de ellas tomadas de las propias redes sociales de las manifestantes (Arteta, 2020).

Estas acciones gubernamentales en contra de las activistas feministas permiten conjeturar la existencia y articulación de mecanismos de vigilancia tanto en las calles públicas, como en las redes virtuales personales de diversas activistas. No es casual que esta investigación haya tenido mayores facilidades para entrevistar a mujeres activistas en

6 Estas acciones de las policías en contra de las activistas feministas fueron observadas mediante el trabajo etnográfico físico y virtual. Los registros de gran parte de las observaciones pueden consultarse en https://www.facebook.com/bhPAZm/videos/?ref=page internal y https://www.facebook.com/LaCaderaDeEva/videos/?ref=page_internal 
comparación con el número de hombres que colaboraron, puesto que el feminismo ha sido desde 2018 y durante la pandemia, la expresión de activistas más visible en los espacios públicos debido a las acciones performativas y violentas que algunas participantes llegan a ejecutar, motivo por el cual puede comprenderse su vigilancia y espionaje por parte de las autoridades judiciales. Muchas de las jóvenes entrevistadas, a diferencia de los hombres, llegaron a mencionar temer por la violencia sexual como un acto de represión y disciplina en su contra. Sobre este punto la activista Paulina, participante de las protestas feministas e integrante de asociaciones civiles y Organizaciones No Gubernamentales (ONG) dedicadas a la atención a violencias contra las mujeres, ha compartido su experiencia:

PAULINA: Un gran logro de los grupos y las colectivas feministas ha sido visibilizar las múltiples violencias a las que estamos expuestas como mujeres y más como activistas. De nuevo, yo siento que las violencias a las que yo estoy expuesta como activista en la CDMX son infinitamente menores a las que está expuesta una amiga mía en Ciudad Juárez (...).

Ganar visibilidad como activista te expone a ser atacada. Pueden ser ataques en línea, puede ser vigilancia, persecución, violación, desaparición. Yo platico con amigos míos activistas y les expreso mi miedo a salir caminando a la calle, y no necesariamente por ser activista, sino por ser mujer. Fui a la GAM (Alcaldía Gustavo A. Madero) y estaba con gente conocida, pero yo siento miedo porque estoy expuesta y mis amigos hombres me dicen que ellos nunca han sentido ese miedo. A mí me pueden asaltar o golpear, eso lo he sabido siempre(...) pero nunca había sentido un miedo a que dañen mi integridad física o que me vayan a desaparecer.

Mi trabajo en Ciudad Juárez me reveló de forma muy gráfica, y tal vez muy explícita, todas las violencias a las que puedo estar expuesta como mujer. Creo que más que estar expuesta a fotografías, fue estar expuesta y a sus testimonios, a sus historias. Me di cuenta de la misoginia que existe en el país [refiere al material de trabajo que utiliza en la Asociación Civil donde labora]. Me contaban de grupos de hombres que se articulan sobre todo en las redes sociales. No es algo exclusivo de Ciudad Juárez, pero me queda claro que existe ahí. Grupos de hombres se articulan para perseguir a activistas y en 
algunos casos acaban en desaparición, en feminicidios, en cuerpos torturados expuestos en las calles.

ENTREVISTADOR: ¿Qué acciones como estas visibilizas en la CDMX?

PAULINA: En la policía hay muchos elementos, hombres y mujeres que pueden cambiar de color de uniforme, pueden ser granaderos armados o no armados, pero tienen mucho rencor y mucho odio hacia las mujeres activistas. Lo vimos en Atenco en el Estado de México, pero también ha ocurrido acá. Si tú estás en una manifestación participando, o no participando, te detienen arbitrariamente te golpean, te levantan, te dan vueltas. Esa es una de las violencias a las que estamos expuestos y en la periferia incluso hay mucho más. Ni siquiera por ser mujer, si tú eres hombre joven y vas caminando por la calle, tú sabes que te pueden levantar. Y estás totalmente expuesto. Puedes traer droga o no traer nada (...).

ENTREVISTADOR: Hacen que la traigas.

PAULINA: Creo que eso es lo más fuerte, ni siquiera creo que tengan que ser hombres identificados bajo una organización (...) Hay ciertas formas de organización de hombres que están diciendo "no queremos que cuestionen nuestro poder”, ¡no! (Paulina, comunicación personal, activista, CDMX, 15 de septiembre de 2020)

Este relato compartido nos permite entrever que existe un matiz de suma importancia en la violencia disciplinaria cuando se trata de mujeres activistas. Muchas de las jóvenes entrevistadas mantienen una inmersión tanto en expresiones del activismo autogestivo o en las afines al trabajo social de la ODS, al mismo tiempo que en el movimiento feminista. Este fenómeno se entiende debido a que el movimiento feminista en la CDMX como en América Latina se viene construyendo paralelamente a otras luchas sociales. Como bien lo expresan las investigadoras Marina Larrondo y Camila Ponce (2019):

Los feminismos y disidencias no solo irrumpen en las calles, en las instituciones políticas y educativas, en nuestra vida cotidiana e íntima, en las formas de relacionarnos, sino también en las identidades juveniles y en el mundo de los activismos y movimientos sociales, atravesándolo todo y transformándolo. (p. 21-22) 
Bajo esta óptica, es posible entender que las mujeres activistas están expuestas a las mismas violencias que cualquier varón activista, además de a una violencia disciplinaria específica con connotaciones sexuales y de género, por el solo hecho de ser mujer y activista.

El conjunto de estos miedos latentes en los y las jóvenes activistas no representa una emoción inalterable, ya que al igual que la emoción del dolor, estos también se canalizan en alegría y se acompañan de un proceso de resistencia manifiesto en una ética común del cuidado (Álvarez y Auyero, 2014; Das, 2012).

\section{Acciones y redes de resistencia y de cuidado}

La vivencia del miedo en los y las activistas representa no solo una acción de temor frente a los actos represivos de las fuerzas policiales y otros actores. Esta emoción se torna importante en primera instancia, ya que al ser transgredida y desafiada genera la acción colectiva. Desde inicios del ciclo de movilizaciones emergido en 2011, Manuel Castells (2012) había detectado la importancia de las emociones en las emergencias de la primavera árabe y los levantamientos de los indignados en el mundo. Para este autor, las redes sociales catapultaban la ira contra la injusticia y la esperanza de cambio en los miles de mensajes e imágenes que circulan en la red. Esta observación dejó en claro que las emociones no solo están presentes en el contacto físico de las personas, sino que estas se desplazan a través del tiempo y el espacio, desafiando fronteras, idiomas, generaciones y horarios por medio del uso de las plataformas tecnológicas.

El miedo, en segunda instancia, también posibilita una serie de estrategias de cuidado y resistencia que buscan tornar la estatización y desmovilización de los activistas en acciones de convivencia, confianza y protección. Este fenómeno se explica principalmente por una profunda desconfianza de los y las activistas en las instituciones estatales. De acuerdo con sociólogo J. Manuel Valenzuela (2015b), en México vivimos un "Estado adulterado" donde el narcotráfico y otros poderes de facto se han inmiscuido en las entrañas de sus instituciones, alterando su razón de ser en una sociedad moderna. Actos como Ayotzinapa ejemplifican la degradación de nuestras instituciones y explican a la vez el desacredito y la crisis de representación del Estado en las actuales juventudes. 
Dado ello, no sorprende que las y los activistas busquen y experimenten estrategias de protección fuera de las instituciones, generando pequeñas prácticas de autoseguridad y protección entre ellos mismos. Estas minúsculas acciones están presentes tanto en la vida cotidiana de estos jóvenes, como en las protestas públicas. Todos las y los entrevistados en esta pesquisa reconocieron realizar un "activismo de bajo perfil" debido a su temor de ser identificados como figuras públicas y ser expuestos a una violencia disciplinaria más aguda.

Es precisamente este bajo perfil el que cumple una doble función en el activismo. Por un lado, evita la visibilización de los activistas ante actores represivos y, por otro, concentra diversas acciones a un nivel barrial y local, como pueden ser la creación de espacios culturales, la impartición de talleres educativos, la producción de alimentos y bienes, la venta y el trueque de saberes y productos autogestionados, y el apoyo técnico y de conocimiento a otros movimientos sociales. La limitación espacial de estas acciones pretende difundir valores horizontales, autónomos y solidarios entre las comunidades locales, practicando otro tipo de relaciones sociales alternativas a las dominantes del sistema capitalista. Es de esta manera que diversas expresiones y muchos activistas adquieren un perfil bajo o subterráneo, pretendiendo con ello consolidar un trabajo de base barrial y local cotidiano que pasa muchas veces desapercibido a pesar de la profundidad cultural de sus impactos (González y Zibechi, 2020). Sobre este punto el activista Fabián menciona las siguientes estrategias:

Respecto de los mecanismos de protección, los hemos aprendido por toda esta violencia que vivimos y que viene a veces desde Ayotzinapa... van desde los códigos de "icomuniquemos dónde estamos!", “iya llegaron?”, que alguien te esté monitoreando, de “¿Qué pasaría si no me reporto?, ¿y si me detienen?" Lamentablemente cada vez son más frecuentes estos mecanismos, dependen también de la actividad que estás realizando y de a dónde vaya uno, del grupo, de la organización con la que vayas, etc.

Hay que reconocer que no todos los y las compañeras quieren implementar estos protocolos. Esta misma reflexión la realizábamos en la ciudad, en los talleres y fue una de las cosas que detonaba conflicto entre los colectivos. Era justo el tema de la seguridad (...) En las marchas es de "no utilizar ese tipo de llamadas", "no utili- 
zar WhatsApp", usar otras plataformas como Telegram por ejemplo, depende la situación. (Fabián, comunicación personal, activista, CDMX, 8 de agosto de 2020)

El testimonio de Fabián ejemplifica la sofisticación de la represión contra los activistas en México. Cuando menciona el caso de Ayotzinapa tiene presente el extremo de la violencia disciplinaria, hablamos de la desaparición de los activistas que causa el dolor de la incertidumbre al no saber si estos han perecido o si aún se encuentran con vida, postergando así el dolor de no poder comenzar un duelo y cargar con el peso de no tener ninguna respuesta.

Estos mecanismos mencionados por Fabián expresan también la desconfianza en las plataformas y aplicaciones virtuales más dominantes como Google, WhatsApp y Facebook, entre otras, las cuales pueden ser fácilmente intervenidas por las autoridades gubernamentales u otros poderes fácticos. Cabe destacar que desde 2016 la Ley Telecom legalizó la obligación de las empresas de telecomunicaciones para darle acceso al poder judicial a los metadatos de los usuarios de dispositivos tecnológicos. Tampoco sobra omitir el espionaje ilegal realizado a periodistas y activistas por parte del gobierno federal del sexenio de Enrique Peña Nieto tras la adquisición del software israelí Pegasus (Ahmed y Perlroth, 2017) 7 . De esta manera, observamos la interpretación del "gobierno cibernético" construida por el Comité Invisible, la cual establece que el propósito de estas normativas es asegurar "enclaves de orden" y regular los sistemas por medio del control de la información (Tiqqun, 2015). En palabras suyas:

Creemos que nuestros datos personales nos pertenecen, como nuestro coche y nuestros zapatos y que, al permitir a Google, Facebook, Apple, Amazon o a la policía tener acceso a ellos estamos ejerciendo inocentemente nuestra "libertad individual", sin darnos cuenta de que hacerlo tiene efectos inmediatos sobre quienes se niegan y que por ello podrían ser tratados sucesivamente como sospechosos, como subversivos en potencia. (Tiqqun, 2015, p. 45)

$7 \quad$ Pegasus es un malware que infecta los teléfonos con sistema operativo Mac OS y Android, permitiendo a sus operadores acceder a mensajes, correos, fotografías, videos, historial de llamadas e incluso activar de manera secreta el micrófono del celular. Entre las personas vigiladas, se encuentran los padres de los 43 normalistas y alrededor de 25 periodistas y directivos de centros para la protección de derechos humanos. 
Es precisamente por este miedo al poder de las grandes empresas de tecnología y de los gobiernos que diversos activistas deciden no usar - o usar poco- estos dispositivos dominantes y preferir el uso de softwares libres o aplicaciones de información encriptada que permita la eliminación de sus mensajes y metadatos. Si bien las tecnologías de la información y comunicación brindan la posibilidad a los activistas de ejercer acciones tecnopolíticas (Toret, 2013) cabe enfatizar como lo ha afirmado la comunicóloga Guiomar Rovira (2019), que también existen actos de contrainsurgencia que desatan una guerra en las redes sociales digitales, pero que también se extrapola a la vida cotidiana de las y los activistas.

Por otro lado, el testimonio de Fabián ejemplifica que frente a la desconfianza en las instituciones de Estado y en las plataformas virtuales y tecnológicas dominantes, la protección y el cuidado queda en manos de los mismos activistas y en sus redes de amistad y solidaridad. Como claro ejemplo de esta ética emergente del cuidado mutuo en la CDMX emergió la etiqueta (hashtag) y la frase \#LaPoliciaNoMeCuidaMeCuidanMisAmigas aludiendo a la denuncia de la violación de una joven menor de edad perpetrada por policías locales (Jiménez, 2019). En este tenor, la activista feminista y afín a las acciones autogestivas, Lulú, comparte su testimonio:

El feminismo me ha dejado la compañía de las otras personas, el no saberte solo o sola, las redes que haces cada día y que compartes con las otras personas, y que vas generando poco a poco con tus cercanos. Y también esa modificación a tu propia vida; por ejemplo, para mí el activismo es desde la bicicleta, un medio de transporte, de autonomía, de seguridad, porque la seguridad no se pide al gobierno, sino que hay que hacerla uno mismo con los suyos (...) tú me preguntabas por la violencia y yo creo que esta nos lleva a la seguridad, y es lo que se ha perdido desde el movimiento feminista (...) pero la vas generando tú, con los tuyos en tu comunidad (...). (Lulú, comunicación personal, activista, CDMX, junio, 2020)

A través de acciones tan cotidianas como la pertenencia a una colectiva de mujeres bicicleteras, Lulú expone su forma de sentirse más libre, fémina, autónoma y segura en las calles y avenidas de la CDMX. A través de este medio de transporte que utiliza desde hace algunos años gracias al activismo y que ha intensificado en la pandemia, Lulú 
se aísla de alguna forma de la violencia sexual en el transporte público, de la delincuencia, del lucro de las empresas propietarias de los buses, de sus reglas y horarios y participa constantemente en movilizaciones feministas públicas, así como en actos solidarios con otros movimientos sociales.

Lulú nos expone con su autorreflexión y su relato la importancia que tienen las redes de amistad dentro de la ética común del cuidado de las y los activistas. La articulación de estas redes es una de las reacciones más sólidas de estos jóvenes a las violencias disciplinarias. Su existencia ha sido posible gracias al tejido de la amistad entre activistas generado en la última década e inclusive años más atrás. Es justo en esta red donde se ofrece una oportunidad para asegurar la vida de sus integrantes, puesto que en ellas los activistas no solo integran los nodos, sino también diversas ODS y organismos internacionales. De igual forma, esta red tiene contradicciones, debido a que ella misma abre la posibilidad de generar espacios para individuos pertenecientes a instituciones estatales, dotando de esta manera de mayores posibilidades de salvaguardar la vida e integridad de las y los activistas.

Si bien esta red de amistad y convivencia se mantiene calma en la vida de los jóvenes activistas, bien puede reaccionar frente a la violencia disciplinaria en momentos de crisis, como cuando uno de sus integrantes se encuentra el alto riesgo. Un claro ejemplo de este mecanismo de cuidado lo encontramos en la activista Paulina, quien nos narra su experiencia frente al peligro al que fue expuesto uno de sus amigos activistas durante el periodo de la pandemia:

Hace como dos o tres semanas desaparecieron a un amigo mío en la entidad de Río Frío. Había ido a un curso con gente del sindicato Obreros Unidos, estuvo incomunicado por 8 horas y lo tenía un comando armado. Digamos que pudo haber sido un desenlace distinto y creo que por tener amigos activistas y por la manera en que nos articulamos y las relaciones que teníamos con la Guardia Nacional, con la Comisión Nacional de Búsqueda, con la ONU, con Amnistía, y con quien tú quieras (...) se permitió visibilizar el caso de tal forma que dijeron "no pues, lo soltamos" y ya no (...).

Entonces creo que, si eso le hubiera pasado a una mujer fuera de esos circuitos, o incluso a una activista fuera del circuito de la 
CDMX, hubiese sido otro desenlace. Y fue muy fuerte porque fue Arturo y otros dos compas de la entidad de Río Frío. E incluso para nosotros cuando comenzamos a articularnos: "es que Arturo" (...) "Arturo" (...) "Arturo" (...) Arturo". Y nos dijo una compañera "a ver" es que son 3 personas, hay otros dos compañeros también" y entonces fue de "iclaro!". "Entiendo que estén preocupados por su amigo, porque lo conocen, pero visibilicemos que también son otras dos personas, son también sus vidas".

Entonces esta articulación sucedió porque Arturo es nuestro amigo y lo apreciamos y claro que nos íbamos a mover. Yo lo que reflexionaba esa noche era que "¡sí me siento expuesta por ser activista!", "por hacer cosas y por irme a meter a Río Frío", pero al final también me siento muy arropada por este grupo de personas que van a hacer todo para encontrarme si desaparezco (...). (Paulina, comunicación personal, activista, CDMX, 15 de septiembre de 2020)

Arturo se encontraba respaldando las acciones de un sindicato fuera de la CDMX. Después de haber participado en diversas movilizaciones durante la última década ha llevado un activismo más individualizado apoyando distintas luchas como un electrón libre (Pleyers, 2018a). A pesar de haber sido previamente una víctima del encarcelamiento y de la represión policial, su vida no se había visto tan comprometida sino hasta este momento en donde el auge de la pandemia parecía opacar las acciones políticas del activismo y la gravedad de la violencia disciplinaria.

El testimonio de Paulina nos muestra el nivel de crudeza de esta violencia a la que están expuestos los y las jóvenes activistas. Si bien la detención de Arturo ocurrió en otra entidad del país, este hecho no omite la exposición de los jóvenes activistas capitalinos a la violencia disciplinaria que trasgrede fronteras y no discrimina jurisdicciones. La vida de Arturo pudo haber terminado muy posiblemente de no haberse activado esta red de amistades y contactos.

Como bien lo señala Paulina, el nivel institucional de esta red, permitió localizar a Arturo a tiempo para evitar un desenlace trágico. Ello deja en claro que el papel del Estado es de vital importancia para la seguridad y el bienestar de los y las activistas, sin embargo, esta protección solo funciona y se agiliza por medio de la lealtad y los vínculos 
de amistad y compromiso personales. Lo cual evidencia la terrible desigualdad que abunda en la procuración y garantía de seguridad y justicia del Estado mexicano. Infelizmente, no cualquier activista o ciudadano cuenta con las ventajas que ha logrado la articulación de esta red.

\section{Conclusiones}

Muy por lo contrario a los enfoques coyunturales o cronológicos de los movimientos juveniles en la última década (Cabrera y Salazar, 2015; González, 2015; Modonesi, 2017), el estudio de los movimientos desde la perspectiva de la subjetividad y en periodos prolongados nos permite entender las transformaciones sociales que se suscitan en la vida cotidiana de las y los activistas, así como la continuidad de la violencia disciplinaria en la que están inmersos.

Si bien los estudios de subjetividad ya han analizado previamente algunos movimientos sociales enfatizando las emociones y los cuidados, sus aportaciones se han visto también limitadas a coyunturas y episodios de las grandes movilizaciones (Nateras, 2019; Loureiro et al., 2013; Poma et al., 2019), por lo tanto, no se ha reflexionado en profundidad que la subjetividad del sujeto trasciende coyunturas y se impregna de experiencias de la vida cotidiana.

Los resultados de esta investigación permitieron exponer la existencia de la continuidad de una década de movimientos sociales manifiesta en las acciones ubicuas de las y los activistas jóvenes de la CDMX que responden a la violencia disciplinaria. La realización de esta pesquisa durante una reflexión de los activistas y con los activistas situada en la pandemia por COVID-19 evidencia que si bien ha habido una disminución de grandes protestas que adquieren visibilidad mediática, los movimientos sociales mantienen una dimensión más cultural y subjetiva, expresada en la canalización de emociones y en la emergencia de conductas de cuidado de las y los activistas.

Al centralizar la vía de la subjetividad (Pleyers, 2018a) en los y las jóvenes activistas enfatizando sus experiencias y experimentaciones en la canalización de emociones (Jaspers, 1998; Platin y Gutiérrez, 1998) y en la ética común del cuidado (Álvarez y Auyero 2014; Das, 2012), se logró observar el papel que tiene la alegría frente a las emociones del dolor y el miedo. La alegría funge como una emoción constructiva y 
esperanzadora que permite a los activistas mantener y experimentar acciones de bajo perfil y subterráneas como salidas a la violencia disciplinaria. Destacan aquí la construcción de proyectos locales como cooperativas, panaderías, talleres temáticos, festivales, la creación de colectivos, de grupos online de trabajo, así como el respaldo y la solidaridad con otros movimientos sociales y la elección de medios de comunicación y transporte más seguros. Estas acciones se han venido construyendo a lo largo de la última década y se han mantenido firmes durante la pandemia por COVID-19.

$\mathrm{Al}$ mismo tiempo, las y los activistas han generado pequeñas estrategias que buscan mantener su seguridad frente a la violencia disciplinaria. La existencia de una red común de cuidado construida por los vínculos de amistad y lealtad entre los propios activistas figura como la estrategia más potente para salvaguardar la vida y el cuidado de sus integrantes. Sin embargo, a pesar de ser una táctica alternativa y emergente debido a la incapacidad del Estado mexicano para garantizar la seguridad e impartición de justicia, esta red muestra limitaciones si no se relaciona con las instituciones estatales. Esto se torna en una paradoja que, más que un problema de contradicción ideológica, representa un problema de desigualdad, ya que evidencia que la garantía estatal de la seguridad solo se ejecuta con eficacia en circuitos reducidos, excluyendo a miles de personas ajenas a estas redes.

Otro de los resultados de esta pesquisa ha sido el entendimiento de la violencia disciplinaria como un acto constante de represión hacia las y los activistas. Esta violencia posee ciertas estructuras sociales y no necesariamente requiere ser localizada y personalizada, ya que puede realizarse de manera virtual, psicológica, e incluso ni siquiera precisa ejecutarse físicamente sobre los cuerpos de los activistas: basta con escarmentar en otros actores cercanos para causar miedo y desmovilización social.

De igual modo, la violencia disciplinaria ha relevado tener matices cuando se direcciona hacia una mujer activista. Esta adquiere mecanismos de represión especializados, como lo son los cuerpos policiales femeninos y el uso de estigmas para enfrentar a las protestas públicas de las últimas movilizaciones feministas. Paralelamente, el matiz de género femenino que atraviesa el activismo dejó entrever la intromi- 
sión de la violencia sexual durante las acciones públicas y la vida cotidiana de las mujeres activistas.

La reflexión del nivel subjetivo de los movimientos sociales realizada durante el confinamiento por la pandemia del virus SARS-CoV-2 ofrece una mirada de los impactos culturales de la violencia disciplinaria cotidiana que afecta a muchos de los y las activistas y que, al mismo tiempo, muestra la inexistencia de una estatización o latencia de los movimientos sociales con protagonismo juvenil, ya que como esta investigación lo demuestra, los activistas mantienen consecuencias subjetivas presentes en sus acciones cotidianas. Con ello es posible entrever que los movimientos sociales, fuera y dentro de la pandemia, no solo están presentes en las protestas multitudinarias y en el ciberactivismo. Las reflexiones y experiencias aquí enunciadas nos ofrecen la posibilidad de entender los cimientos del cambio social como salida tanto a la crisis sanitaria, como a la civilizatoria.

\section{Referencias}

Andrade, H. (2018). Prácticas políticas juveniles contemporáneas. Los casos de \#YoSoy132 y \#TodosSomosPolitecnico en Ciudad de México y Movimiento Passe Livre y de los Secundaristas en Ciudad de São Paulo-Brasil [Tesis de maestría no publicada]. Universidad Nacional Autónoma de México, UNAM.

Almed, A. y Perlroth, N. (18 de junio de 2017). 'Somos los nuevos enemigos del Estado': el espionaje a activistas y periodistas en México. The New York Times.

https://www.nytimes.com/es/2017/06/19/espanol/ america-latina/mexico-pegasus-nso-group-espionaje.html

Álvarez, L. (2020). El movimiento feminista del siglo XXI en México, juventud, radicalidad y violencia. Revista Mexicana de Ciencias Políticas y Sociales, 65(240), 147-175. http://dx.doi. org/10.22201/fcpys.2448492xe.2020.240.76388

Álvarez, L. y Auyero, J. (2014). "La ropa en el balde". Rutinas y ética popular frente a la violencia en los márgenes urbanos. Nueva Sociedad, ¿Contra el sistema? Jóvenes, luchas y disidencias en el siglo XXI, (251), 17-30.https://biblat.unam.mx/hevila/ Nuevasociedad/2014/no251/2.pdf

Ariza, M. (2016). Introducción. La sociología de las emociones como plataforma para la investigación social. En M. Ariza. 
(Coord.), Emociones, afectos y sociología. Diálogos desde la investigación social y la interdisciplina (pp. 7-34). Instituto de Investigaciones Sociales, IIS Universidad Nacional Autónoma de México, UNAM.

Arteta, I. (25 de noviembre de 2020). Fiscalía de la CDMX abre investigación contra 13 jóvenes feministas. Animal Político. https://www.animalpolitico.com/2020/11/fiscalia-cdmxabre-investigacion-contra-13-jovenes-feministas/

Bringel, B. y Pleyers, G. (2020). Alerta global. Políticas, movimientos sociales y futuros en disputa en tiempos de pandemia. Consejo Latinoamericano de Ciencias Sociales, CLACSO.

Bringel, B. (2020). Mucho más que un cacerolazo: resistencias sociales en tiempos de pandemia. En B. Bringel y G. Pleyers (Eds), Alerta global. Políticas, movimientos sociales y futuros en disputa en tiempos de pandemia (pp. 181-187). Consejo Latinoamericano de Ciencias Sociales, CLACSO.

Cabrera, R. y Salazar, C. (2015). Nos quieren enterrar, olvidan que somos semillas, el devenir de las nuevas insurgencias. Universidad Autónoma Metropolitana, UAM.

Castells, M. (2012). Redes de indignación y esperanza. Alianza Editorial. Das, V. (2012). Ordinary ethics: The perils and pleasures of everyday life. En D. Fassin(Ed.), A companion to moral anthropology (pp. 133-149). Wiley-Blackwell.

Dowbor, M. y Szwako, J. (2016). Innovación y reproducción: Repertorios y modalidades organizativas de los movimientos por el derecho a la ciudad en metrópolis brasileñas. En L. Álvarez (Coord.), Ciudadanía y nuevos actores en grandes ciudades (pp. 187204). Universidad Nacional Autónoma de México, UNAM.

El Economista. (29 de enero de 2021). En 2020 se localizaron 559 fosas clandestinas en México: Alejandro Encinas. El Economista. https://www.eleconomista.com.mx/politica/En-2020-selocalizaron-559-fosas-clandestinas-en-Mexico-AlejandroEncinas-20210129-0054.html

Floridi,L.(2015). The onlinemanifesto:Being humanina hyperconnected era. Springer Open.

Foucault, M. (1976). Vigilar y castigar. Siglo XXI Editores.

Giugni, M. (2008). Political, biographical, and cultural consequences of social movements. Sociology Compass, 2(5), 1582-1600. https://doi.org/10.1111/j.1751-9020.2008.00152.x 
González P. (2017). Las nuevas ciencias y las humanidades, de la academia a la política. Consejo Latinoamericano de Ciencias Sociales, CLACSO.

González, F. yZibechi, R. (11 de mayo de 2020). Barrios en movimiento, los espacios autónomos enlaCiudad de México.Desinformémonos. https://desinformemonos.org/barrios-en-movimiento-losespacios-autonomos-en-la-ciudad-de-mexico/

González, R. (2015). Ayotzinapa. La rabia y la esperanza. Terracota.

Hart, S. (1996). The cultural dimension of social movements: A theoretical assessment and literature review. Sociology of Religion, (57), 87-100. https://doi.org/10.2307/3712006

Jasper, J.(1998). The emotions of protest: Affective and reactive emotions in and around social movements. Sociological Forum, (13), 397-424. http://dx.doi.org/10.1023/A:1022175308081

Jasper, J. (2012). Las emociones y los movimientos sociales: veinte años de teoría e investigación. Revista Latinoamericana de Estudios sobre Cuerpos, Emociones y Sociedad, (10), 48-68. https://www.redalyc.org/pdf/2732/273224904005.pdf

Jiménez, G. (6 de agosto de 2019). Policías someten y violan a menor en Azcapotzalco. Excelsior. https://www.excelsior.com. $\mathrm{mx} /$ comunidad/policias-someten-y-violan-a-menor-enazcapotzalco/1328672

Larrondo, M. y Ponce, C. (2019). Activismos feministas jóvenes: emergencias, actrices y luchas en América Latina. Consejo Latinoamericano de Ciencias Sociales, CLACSO.

Loureiro, I., Judensnaider, E., Lima, L., Ortellado, P., Pomar, M., (2013). Vinte centavos: a luta contra o aumento. Veneta.

Modonesi, M. (2017). Militancia, antagonismo y politización juvenil entre el \#YoSoy132 y Ayotzinapa. Universidad Nacional Autónoma de México, UNAM.

Nateras, A. (2019). Juventudes sitiadas y resistencia afectivas, acción colectiva e identidades, Tomo III. Gedisa.

Plantin, C. y Gutiérrez. S. (2009). La construcción política del miedo. En P. Bentivoglio, F. Erlich y M. Shiro (Comps.), Haciendo discurso. Homenaje a Adriana Bolivar; (pp. 491-509). Universidad Central de Venezuela.

Pleyers, G. (2018a); Movimientos sociales en el siglo XX. Consejo Latinoamericano de Ciencias Sociales, CLACSO. 
Pleyers, G. (21 de noviembre de 2018b). The new repertoire of repression and how movements resist. Introduction. Opendemocracy. https://www.opendemocracy.net/en/new-repertoire-ofrepression-and-how-movements-resist/

Poma, A. (2017). Defendiendo territorio y dignidad. Emociones y cambio cultural en luchas contra represas en España $y$ México. Universidade Estadual da Paraíba, EDUEPB, Red WATERLAT-GOBACIT, Universidad Iteso de Guadalajara.

Poma, A. y Gravante, T. (2016). “Fallas del sistema.' Un análisis desde abajo del movimiento anarcopunk en México. Revista Mexicana de Sociología, 78(3), 437-467. http://www. scielo.org. $\mathrm{mx} /$ scielo.php?script=sci_abstract\&pid=S018825032016000300437\&lng=en\&nrm=iso\&tlng=es

Poma, A., Gravante, T., y Paredes, J. (2019). Editorial. Resistencias $\mathrm{y}$ emociones del activismo en contextos represivos, autoritarios o violentos. Una introducción. Polis, (53). http:// journals.openedition.org/polis/17384

Reguillo, R. (2017). Paisajes insurrectos jóvenes, redes y revueltas en el otoño civilizatorio. NED ediciones.

Reguillo, R. (2015). \#Ocupalascalles \#Tomalasredes. Disidencias, insurgencias y movimientos juveniles: del desencanto a la imaginación política. En J. Valenzuela (Coord.), El sistema es antinosotros, culturas, movimientos y resistencias juveniles (pp. 129-156). Gedisa, Universidad Autónoma Mexicana, UAM y Colegio de la Frontera Norte, COLEF.

Reguillo, R. (2011). Juventud en exequias: violencias, precarización y desencanto.Conspiratio $n^{\circ} 12$. Violencia de Estado: el fracaso de la transición. Editorial Jus.

Reguillo, R. (2005). Ciudades y violencias. Un mapa contra los diagnósticos fatales. En R. Reguillo y R. Marcial (Eds.), Ciudades translocales. Espacios, flujos, representación. Instituto Tecnológico y de Estudios Superiores de Occidente, ITESO-Social Science Research Council, SSRC.

Reza, A. (26 de febrero de 2020). En enero de 2020, cada día 10 mujeres fueron asesinadas. Milenio. https://www.milenio.com/ policia/en-enero-de-2020-cada-dia-10-mujeres-fueronasesinadas

Romanos, E. (2016). De Tahrir a Wall Street por la Puerta del Sol: la difusión transnacional de los movimientos sociales en 
perspectiva comparada. Revista Española de Investigaciones Sociológicas, (154), 103-118. http://dx.doi.org/10.5477/cis/ reis.154.103

Rosenbaum, J. y Sederberg, P. (1975). Vigilantism: An analysis of establishment violence. En J. Rosenbaum y P. Sederberg (Eds.), Vigilante politics. University of Pennsylvania Press.

Rovira, G. (2019). Tecnopolítica para la emancipación y para la guerra: acción colectiva y contrainsurgencia. Revista Científica de Información y Comunicación, (16), 39-83. https://icjournalojs.org/index.php/IC-Journal/article/view/526

Santos de Sousa, B. (2006). Conocer desde el sur. Para una cultura política emancipatoria. Universidad Nacional Mayor de San Marcos, UNMSM.

Santos de Sousa, B. (2003). Crítica de la razón indolente. Contra el desprecio de la experiencia, Vol. 1. Desclée de Brouwer.

Saúl, D. (25 de agosto de 2019). 10 mujeres son asesinadas cada día en México, 312 son víctimas de un delito. El Financiero. https:// www.elfinanciero.com.mx/nacional/al-dia-312-mujeresson-victimas-de-un-delito-en-mexico-10-son-asesinadas

Tiqqun, (2015). La hipótesis cibernética "A propósito de Tiqqun" de Giorgo Agamben "Fuck off Google" del Comité Invisible. Acuarela y A. Machado.

Toret, J. (2013). Tecnopolítica. La potencia de las multitudes conectadas. El sistema red $15 M$ un nuevo paradigma de la política distribuida. Universitat Oberta de Catalunya.

Valenzuela, J. (2015a). El sistema es antinosotros, culturas, movimientos y resistencias juveniles. Gedisa, Universidad Autónoma Mexicana, UAM y Colegio de la Frontera Norte, COLEF.

Valenzuela, J. (2015b). Juvenicidio, Ayotzinapa y las vidas precarias en América Latina. NED Editores. 